\title{
DEVELOPMENT OF GLOBAL VACUUM PRESSURE IMPREGNATION INSULATION SYSTEM FOR TURBINE GENERATORS
}

\author{
Akinobu Nakayama, Kohji Haga, Seiichi Inoue \\ Fuji Electric Corporate Research and Development, Ltd. \\ 1-1 Tanabeshinden Kawasaki-ku, Kawasaki-city 210-8530, Japan
}

Key Words: VPI insulation system, stator winding, turbine generator, post impregnation insulation system

\begin{abstract}
Global vacuum pressure impregnation insulation system exhibits various merits in insulation performance and reliability for operation including maintenance. Therefore, the system is suitable for ordinary turbine generators, especially, the generators for geothermal power plant.

We have developed a global vacuum pressure impregnation insulation system (F-resin/GII insulation system) for large size turbine generators and had put into practical use in 1993.

In the process of evaluation of insulation system, we evaluated impregnating ability, electrical, and mechanical characteristics.

From evaluation, we were able to achieve the improvement of heat cycle, heat resistance and V-t characteristics against usual insulation system, because of the utilization of internal electrical field relaxation layer, thermal stress relaxation layer, insulation tapes with excellent impregnation ability and epoxy resin with high heat resistance.

As the insulation characteristics are affected not only utilized materials and their composition but also manufacturing process, it is reasonable to suppose that we can obtain the improvement of insulation performances and stabilization of quality by using the taping simulation technique.
\end{abstract}

\section{INTRODUCTION}

Fuji Electric has developed a global vacuum pressure impregnation insulation system (F-resin/G II insulation system) for large size turbine generators together with introduction of required manufacturing equipment since 1990, and had put into practical use in 1993. After that, numerous generators have been manufactured utilizing this insulation system and have been operated successfully.

In the global vacuum impregnation insulation system, stator winding inserted into stator is immersed in epoxy resin, and is impregnated under vacuum and pressure. Through this VPI process not only the coil insulation is formed but also the resin penetrates into stator slot clearance, wedges and coils. Additionally, all stator parts are coated by the resin. Furthermore, the stator coil insulation is impregnated by the resin continuously and rigidly from slot portion to coil end conductor connecting portion.

Therefore, there are a lot of merits such as high reliability of winding, no looseness of stator core, corrosion proof, prevention of coil vibration as well as excellent heat conductivity from the conductor to the core owing to filling up of stator slot clearance by the resin. Furthermore, replacement of wedges are not required because no wedge looseness is induced. These features are suitable for ordinary turbine generators, especially, the generators for geothermal power plant, surrounded by atmosphere containing hydrogen sulfide

Though this insulation system is mainly applied to air cooled turbine generators with output range of from 20 to 260MVA, it is also possible to manufacture hydrogen cooled turbine generators with output range of from 50 to 340MVA, utilizing the merits of global vacuum pressure impregnation insulation system. Table 1 shows standard specifications of turbine generators applied the F-resin/G II insulation system and Figure 1 shows appearance of 126MVA air cooled turbine generator stator.

\section{FEATURES OF F-RESIN/GIINSULATUION SYSTEM}

Global vacuum pressure impregnation insulation system retains many merits such as improvement of insulation performances, stabilization of quality, shortening of manufacturing period and mitigation of maintenance load. In particular, since an thermal stress relaxation layer is provided in the F-resin/GHinsulation system, a stable heatcycle resistance characteristic is realized and enables to serve for the DSS (daily start and stop) operation mode which corresponds to current power demand.

The main features of the F-resin/GIinsulation system are listed below, and Figure 2 shows cross section of winding.

- Utilization of epoxy impregnation resin with long enduring life and high heat resistance.

- Utilization of main insulation tapes with excellent impregnation ability.

- Utilization of internal electrical field relaxation layer

- Utilization of thermal stress relaxation layer 


\section{EVALUATION TEST RESULTS ON MODEL COILS}

\subsection{Impregnating ability characteristics}

The most important factor in the global vacuum pressure impregnation insulation technique is that the resin should be penetrated sufficiently into the insulation layers at the time of impregnation.

In order to achieve this requirement, a test for impregnating velocity by measuring electrostatic capacity is performed to select the main insulation tapes. The main insulation tape is comprised of mica paper, glass cloth, binder and accelerator. The factors to affect the impregnation are kind and quantity of the accelerator, kind and quantity of the binder, tension of taping work, air permeability of the tape and viscosity of the resin.

Fuji Electric has selected several main insulation tapes appropriate to this insulation system through the various tests for impregnating ability. The impregnating ability characteristic of these tapes is shown in Fig. 3. The characteristics shown in Fig. 3 are that of model coils, and the impregnation process completed within about 140 minutes, and it is obvious that all tapes have the characteristics appropriate for the high voltage insulation.

\subsection{Heat cycle characteristics}

Figure 4 and 5 shows $\tan \delta-\mathrm{V}$ characteristics and partial discharge characteristics respectively during heat cycle test up to 400 cycles. The test coils on $16.5 \mathrm{kV}$ class are composed of guard electrodes and are provided with both an internal electrical field relaxation layer as well as a thermal stress relaxation layer.

As shown in Figure 4, the $\tan \delta-\mathrm{V}$ characteristic after 400 heat cycles is getting worse a little, affected by cracks and voids inside the insulation layers due to the heat cycles, however, it still preserves enough margin for an allowable limit.

Furthermore, it is known in Figure 5, that the partial discharge increases a certain degree in relation to heat cycles, however, it is deemed as stable since an increasing rate of partial discharge is rather small.

In generally, cracks and microscopic voids will be generated in the insulation wall by repeated expansion and contraction consequent upon the heat cycles, therefore the insulation characteristics after heat cycles become worse. However, thermal stress relaxation layer provides an ability to obstruct the invasion of cracks resulted from heat cycle into main insulation wall, while internal electrical field relaxation layer relaxes electric field strength nearby conductors. It is supposed that heat cycle characteristics was improved by these effects.

\subsection{Heat resistance characteristics}

Through the utilization of a resin hardener with high heat resistance for this insulation system, the heat resistance characteristics of insulation wall have been remarkably improved.
Figure 6 shows dielectric strength of test coils on $16.5 \mathrm{kV}$ class that have heated to $160^{\circ} \mathrm{C}$ and $180^{\circ} \mathrm{C}$ during 3000 hours. It is clearly understood that the test coils have superior dielectric strength at initial condition, and it is kept almost at the same level even after the heating of 3000 hours.

\subsection{V-t characteristics}

The dielectric strength is decreased by voltage application during long term. Figure 7 shows $\mathrm{V}-\mathrm{t}$ characteristics of test coils on $16.5 \mathrm{kV}$ class with/without the internal electrical field relaxation and thermal stress relaxation layer. Though the dielectric strength at earlier phase are almost identical regardless of existence of relaxation layers, the test coils of relaxation layers model demonstrate longer life with the time than others against the identical electric field.

\subsection{Mechanical Characteristics}

Figure 8 shows repeated bending fatigue test results for both the F-resin/G II insulation system (mica paper + glass tape) and the conventional insulation system (flake mica + fleece based tape).

The F-resin/G II insulation system demonstrates higher toughness compared with the conventional one.

The big fatigue characteristic differences between both insulation systems are resulted from difference of used materials. One of major factors is composition of mica. In case of flake mica, since wide cracks are formed by exfoliation of mica flake due to bending stress, break down voltage may be decreased. On the contrary, in case of mica paper, since impregnation resin is penetrated without voids due to fine mica particles, exfoliation of mica particles due to bending stress may be small. Furthermore, glass base (glass cloth) is utilized for F-resin/G I insulation, while fleece base (unwoven polyester fabric) is utilized for conventional insulation. Improvement of fatigue strength may be attributable to higher mechanical strength of insulation with glass base.

\section{MANUFACTURING METHOD AND INSULATION CHARACTERISTICS FOR ACTUAL GENERATOR}

\subsection{Simulation technology of taping}

Insulation characteristics of stator coils are affected not only the applied materials but also the manufacturing method. For an example, taping method of main insulation tapes causes a change of BVD characteristics. Therefore, it is essential to secure the stable insulation characteristics with the help of the optimum taping conditions.

Figure 9 and 10 shows an analyzed example by computer program originally developed by Fuji Electric, which enables verification of taping conditions. Figure 9 shows layer state of insulation wall over longitudinal cross section of a coil. Figure 10 shows isolayers distribution over coil insulation surface.

The essential point to manufacture high reliable coils is to 
avoid the reduction of number of layers at corners of coil section shown in Figure 10. The taping parameters obtaining from the simulation are inputted into automatic taping machine and machine's controller controls the taping condition to optimum.

Figure 9 and 10 show analysis result in case of both-way taping with half lap. Fuji Electric has performed impregnating speed test and insulation test for both-way taping and one-way taping, and has confirmed already that both taping method shows equivalent insulation characteristics.

\subsection{Insulation characteristics on actual generator}

Figure 11 and 12 shows $\tan \delta-\mathrm{V}$ and $\mathrm{Qmax}-\mathrm{V}$ characteristics respectively, on the 126MVA turbine generator manufactured in May 1998 utilizing the manufacturing equipment and the insulation system described above. These results demonstrate satisfactory characteristics for both $\tan \delta-\mathrm{V}$ and $\mathrm{Qmax}-\mathrm{V}$.

\section{CONCLUSION}

These results lead to the following conclusion.

(1)In this insulation system, we were able to achieve the improvement of heat cycle, heat resistance and V-t characteristics because of the utilization of internal electrical field relaxation layer, thermal stress relaxation layer, insulation tapes with excellent impregnation ability and epoxy resin with high heat resistance.

(2)As the insulation characteristics are affected not only utilized materials and their composition but also manufacturing process, it is reasonable to suppose that we can obtain the improvement of insulation performances and stabilization of quality by using the taping simulation technique.

This global vacuum pressure impregnation insulation system exhibits various merits in insulation performance and reliability for operation including maintenance, and therefore suitable for the generators used at geothermal power plant. Additionally, the global vacuum pressure impregnation insulation system is attracted as a leading system for the insulation in future.

\section{REFERENCES}

[1]A.Nakayama, T.Tujimura, K.Haga. (1994). Development of Vacuum Pressure Impregnation Insulation System for Turbine Generator. The Institute of Electrical Engineers of Japan. DEI-94-60

[2]A.Nakayama. (1995). Evaluation of Mechanical Characteristics for a New Vacuum Pressure Impregnation Insulation System. 1995 ISEIM, P45

[3]A.Nakayama. (1998). Development of Global Vacuum Pressure Impregnation Insulation System for Turbine Generators. 1998 ISEIM, P2-38
Tab.1 Standard specifications of turbine generators applied F-resin/Gாinsulation system

\begin{tabular}{|c|c|c|}
\hline Items & Air cooled & $\begin{array}{c}\text { Hydrogen indirect } \\
\text { cooled }\end{array}$ \\
\hline Output & $\begin{array}{c}20 \sim 260 \mathrm{MVA} \\
(50,60 \mathrm{~Hz})\end{array}$ & $\begin{array}{c}50 \sim 340 \mathrm{MVA} \\
(50,60 \mathrm{~Hz})\end{array}$ \\
\hline Voltage & $11 \sim 16 \mathrm{kV}$ & $11 \sim 22 \mathrm{kV}$ \\
\hline $\begin{array}{c}\text { Insulation } \\
\text { class }\end{array}$ & F class & F class \\
\hline
\end{tabular}

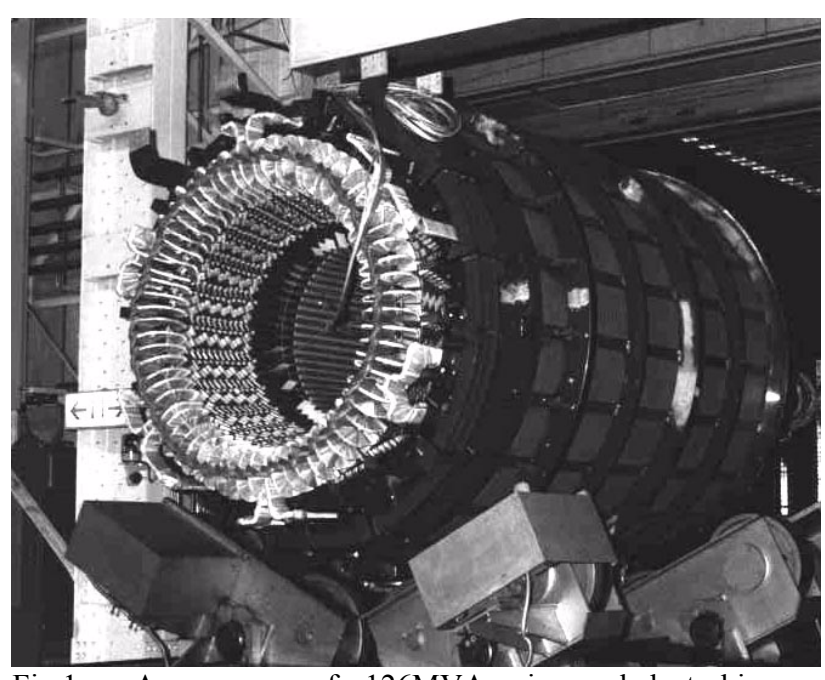

Fig.1 Appearance of 126MVA air cooled turbine generator stator.



Fig.2 Cross section of winding. 




Fig.3 Impregnating ability characteristics on mica tapes.

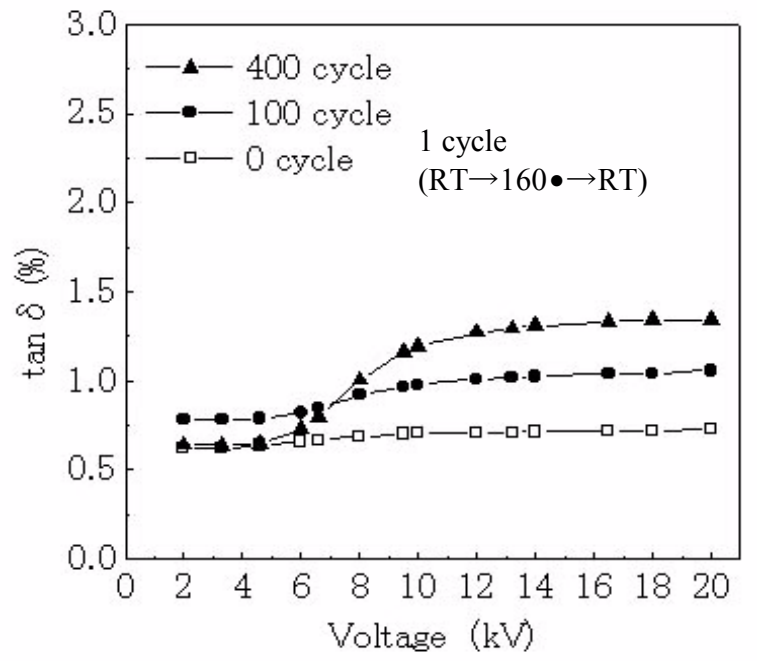

Fig.4 $\tan \delta-V$ characteristics in heat cycle test

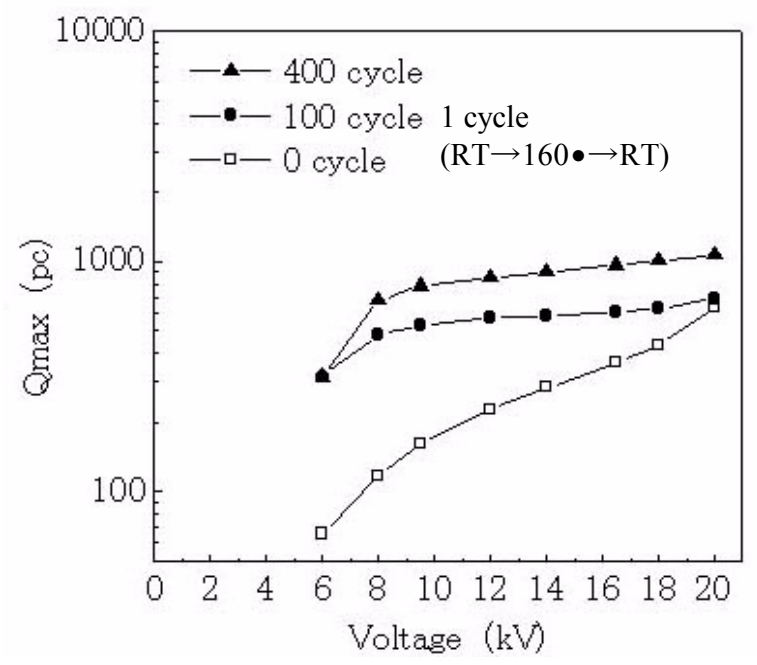

Fig.5 Qmax-V characteristics in heat cycle test.

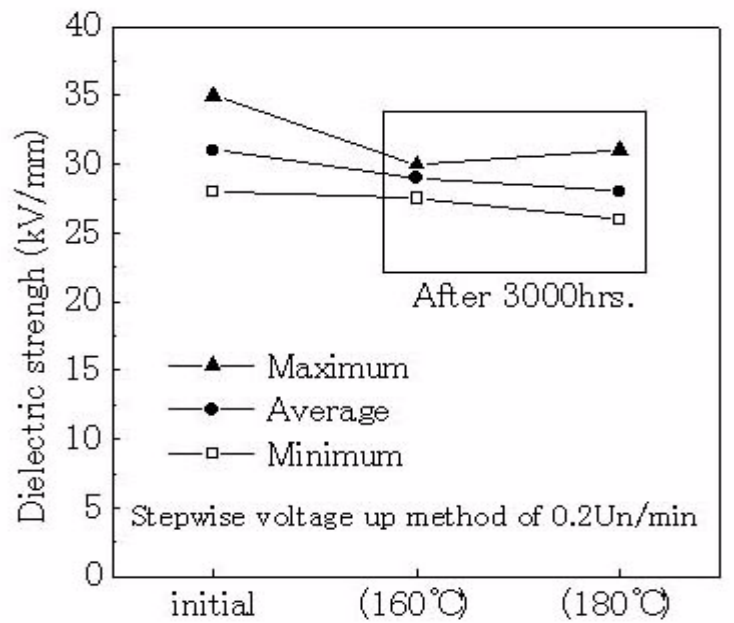

Fig.6 BDV characteristics in long-term heating test of 3000 hours.

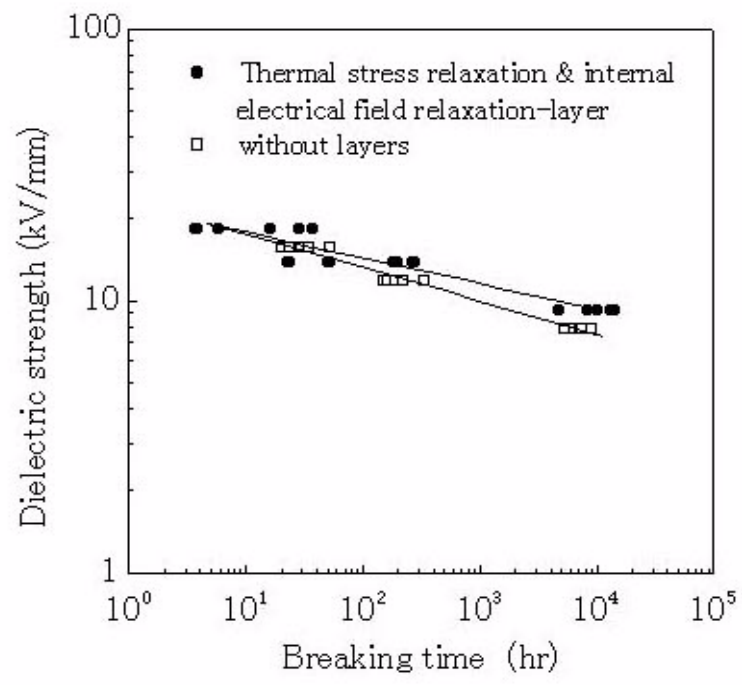

Fig.7 V-t characteristics.

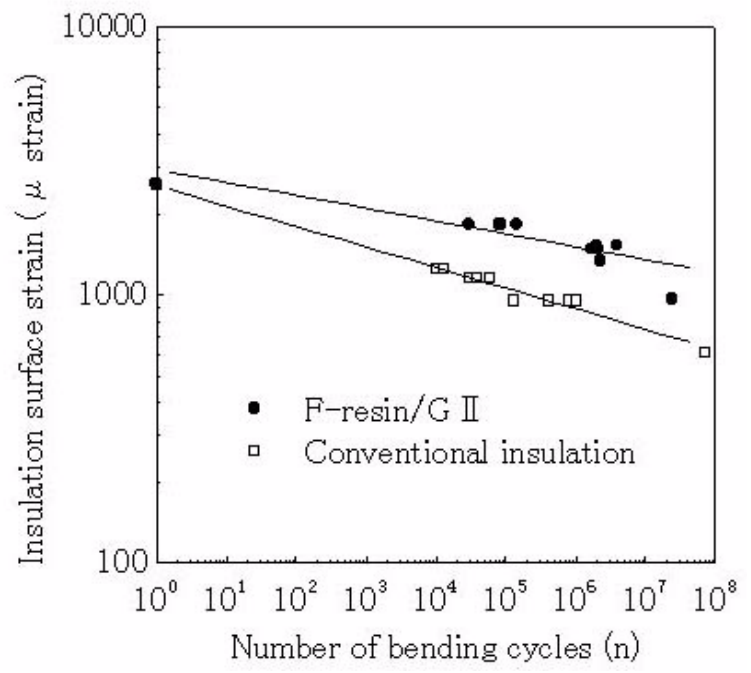

Fig.8 Relation between number of bending cycles and insulation surface strain. 


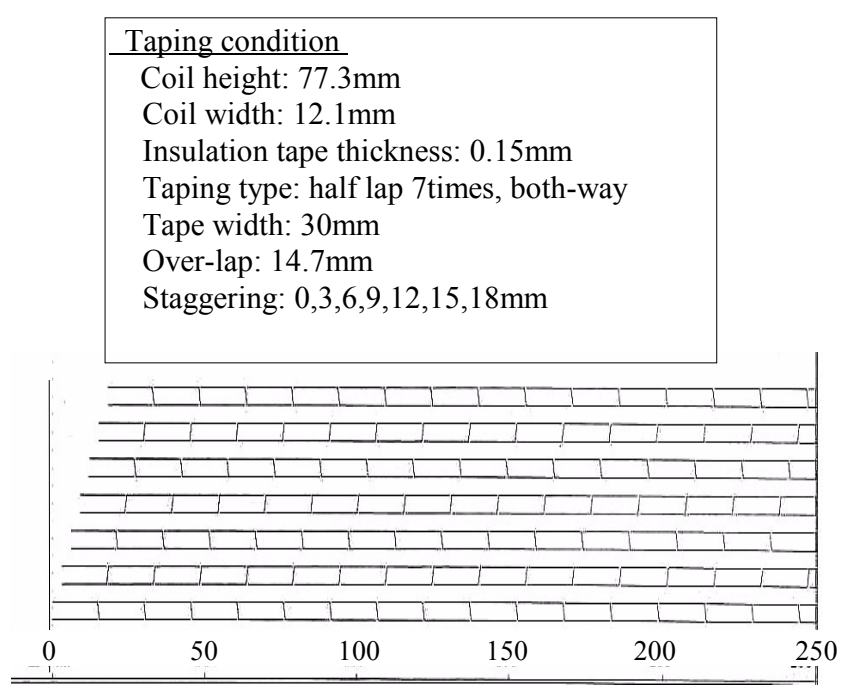

Fig.9 Longitudinal cross section of insulation wall

\begin{tabular}{|cl|}
\hline Layers & Isolayers distribution ratio \\
\hline 14 & $74.33 \%$ \\
13 & $23.87 \%$ \\
12 & $1.8 \%$ \\
& \\
Number of minimum over-lap layers: 12 & \\
Insulation layers filling ratio: $98.04 \%$ & 14 \\
& 12 \\
\end{tabular}

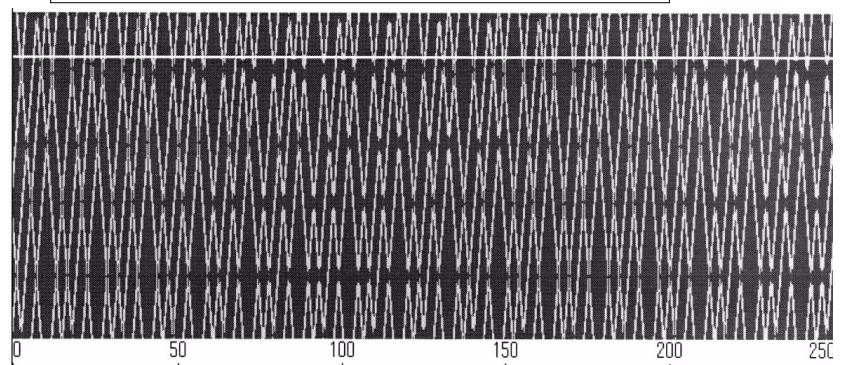

Fig.10 Isolayers distribution over coil insulation surface.

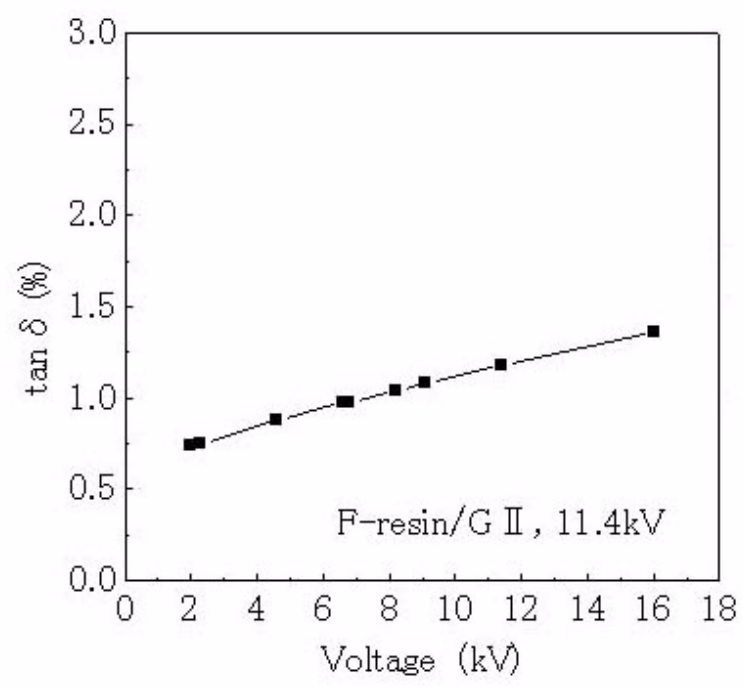

Fig.11 $\tan \delta-\mathrm{V}$ characteristics on the 126MVA turbine generator

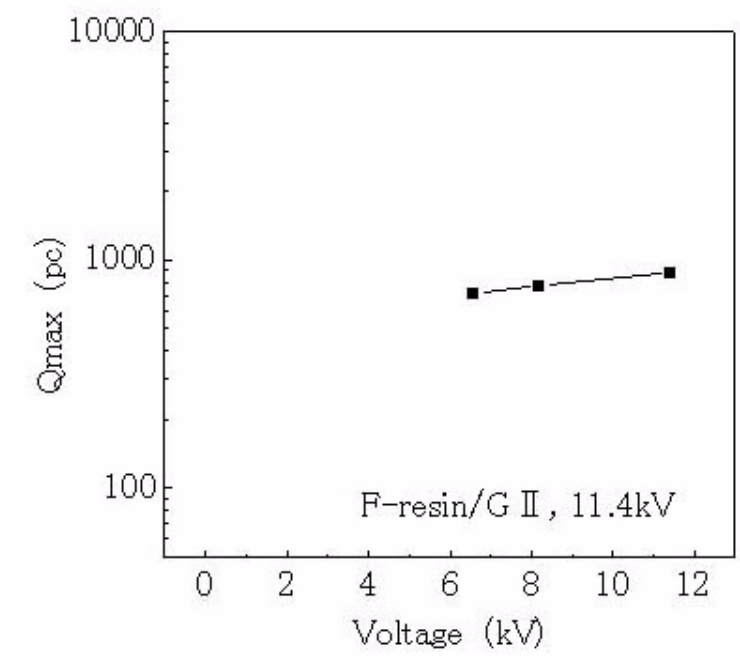

Fig.12 Qmax-V characteristics on the 126MVA turbine generator. 